\title{
Elimination of GRK2 from Cholinergic Neurons Reduces Behavioral Sensitivity to Muscarinic Receptor Activation
}

\author{
Tanya L. Daigle ${ }^{1}$ and Marc G. Caron ${ }^{1,2}$ \\ Departments of ${ }^{1}$ Cell Biology and ${ }^{2}$ Neurobiology, Duke University Medical Center, Durham, North Carolina 27710
}

\begin{abstract}
Although G-protein-coupled receptor kinase 2 (GRK2) is the most widely studied member of a family of kinases that has been shown to exert powerful influences on a variety of G-protein-coupled receptors, its role in the brain remains largely unknown. Here we report the localization of GRK2 in the mouse brain and generate novel conditional knock-out (KO) mice to assess the physiological importance of this kinase in cholinergic neurons. Mice with the selective deletion of GRK2 in this cell population (ChAT ${ }^{\mathrm{IRES}-\mathrm{cre}} \mathrm{Grk} 2^{\mathrm{f} / \mathrm{f}} \mathrm{KO}$ mice) exhibit reduced behavioral responsiveness to challenge with oxotremorine-M (0xо-M), a nonselective muscarinic acetylcholine receptor agonist. Specifically, Oxo-M-induced hypothermia, hypolocomotion, and salivation were markedly reduced in these animals, while analgesic responses were unaltered. In contrast, we found that GRK2 deficiency in cholinergic neurons does not alter cocaine-induced psychomotor activation, behavioral sensitization, or conditioned place preference. These results demonstrate that the elimination of GRK2 in cholinergic neurons reduces sensitivity to select muscarinic-mediated behaviors, while dopaminergic effects remain intact and further suggests that GRK2 may selectively impair muscarinic acetylcholine receptor-mediated function in vivo.
\end{abstract}

\section{Introduction}

Regulation of G-protein-coupled receptor (GPCR)-mediated signaling and trafficking by G-protein-coupled receptor kinases (GRKs) is fundamental to many diverse neurobiological processes. This family of kinases consists of seven distinct members (GRK1-7), all of which have been shown to promote GPCR desensitization via phosphorylation of the agonist-activated receptor. Five of the GRKs (GRK2-6) are expressed to varied extents in the brain (Premont and Gainetdinov, 2007). Germline deletion of GRK5 or GRK6 in mice results in a myriad of centrally mediated phenotypes including altered sensitivity to muscarinic agonists, psychostimulants, and antipsychotic drugs (Gainetdinov et al., 1999, 2003; Raehal et al., 2009; Managò et al., 2012). GRK2 is unique within this family because it is the only isoform whose germline deletion in mice results in embryonic lethality, leaving the physiologic function of GRK2 in the adult brain relatively unknown (Jaber et al., 1996). Several studies have reported brain region-specific changes in GRK2 expression levels following pharmacological treatments that target the dopamine system, such as 6-hydroxydopamine and cocaine (Bezard et al., 2005; Ahmed et al., 2008b; Schroeder et al., 2009). In addition, increased GRK2 levels were also reported in the frontal cortex of fragile X mental retardation protein (FMRP)-deficient mice

Received May 7, 2012; revised June 25, 2012; accepted July 8, 2012.

Author contributions:T.L.D. designed research; T.L.D. performed research; T.L.D. and M.G.C. analyzed data; T.L.D. and M.G.C. wrote the paper.

This work was supported by NIH Grants DA030026 (T.L. Daigle) and MH073853 (M.G. Caron). We thank Dr. Gerald Dorn II for generously providing the floxed Grk2 mouse line, Dr. Brigid Hogan for providing the Rosa26-EYFP reporter mouse line, and Xiuqin Zhang for excellent assistance with the mouse husbandry. We also thank Dr. Raul Gainetdinov, Dr. Richard Premont, and Dr. Jonathan Ting for providing comments on the manuscript.

Address correspondence to either Dr. Tanya L. Daigle or Dr. Marc G. Caron, at the above address. E-mail: t.daigle@cellbio.duke.edu or m.caron@cellbio.duke.edu.

DOI:10.1523/JNEUROSCI.2234-12.2012

Copyright $\odot 2012$ the authors $\quad 0270-6474 / 12 / 3211461-06 \$ 15.00 / 0$
(Wang et al., 2008). However, the physiological consequences of altered GRK2 levels are unclear in most of these contexts and the role of GRK2 in the expression of dopamine-associated behaviors has never been thoroughly investigated. Furthermore, given the lack of information regarding the cellular populations containing GRK2 in the brain, it is difficult to pinpoint the principal cell type in which these changes are occurring.

In this study, we report the expression pattern of GRK2 throughout the mouse brain and demonstrate that within the striatum, GRK2 is predominantly expressed in cholinergic interneurons. To better understand the role of GRK2 in cholinergic neurons, we generated conditional knock-out $(\mathrm{KO})$ mice and performed behavioral analyses on naive and drug-stimulated animals. We demonstrate that GRK2 deficiency does not grossly alter the behavior of these animals but, rather, results in a marked reduction in responsiveness to muscarinic receptor stimulation.

\section{Materials and Methods}

Animals. All animal studies were conducted with an approved protocol from the Duke University Institutional Animal Care and Use Committee in accordance with National Institutes of Health guidelines. C57BL/6J and ChAT TRES-cre mice (stock \#006410) were purchased from Jackson Laboratories. Floxed Grk2 mice were obtained from Dr. Gerald Dorn II (Washington University, St Louis, Missouri) (Matkovich et al., 2006) and Rosa26-floxed-stop-EYFP reporter mice were obtained from Dr. Brigid Hogan (Duke University). Experimental animals were generated by crossing homozygous floxed mice to homozygous floxed mice that were also heterozygous for cre $\left(G r k 2^{\mathrm{f} / \mathrm{f}}\right.$ $\left.\times C h A T^{I R E S-\mathrm{cre}} G r k 2^{\mathrm{f} / \mathrm{f}}\right)$. These breedings yielded $C h A T^{I R E S-\mathrm{cre}} G r k 2^{\mathrm{f} / \mathrm{f}}$ mice (KO animals) and $G r k 2^{\mathrm{f} / \mathrm{f}}$ littermates (control animals). Drugand experiment-naive adult mice (2-6 months of age and of mixed sex) were used for all studies.

Drugs. Cocaine hydrochloride and Oxotremorine-M were purchased from Sigma-Aldrich and Tocris Biosciences, respectively. Drugs were 
A

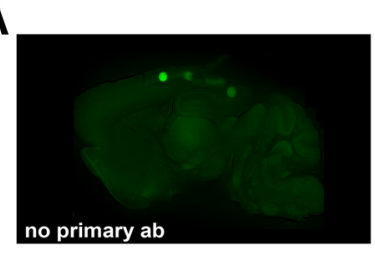

B

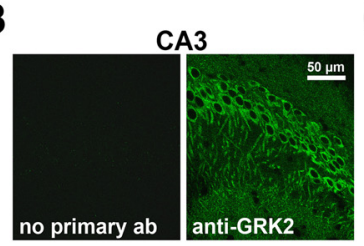

D

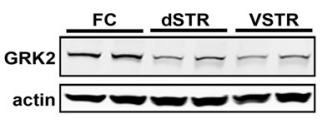

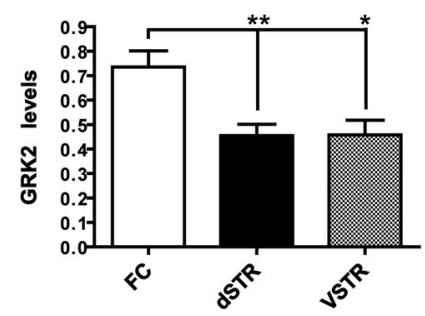

E

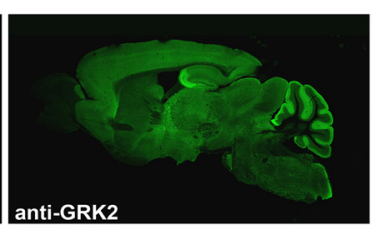

C

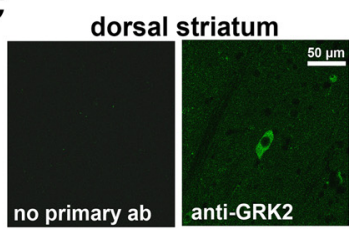

G
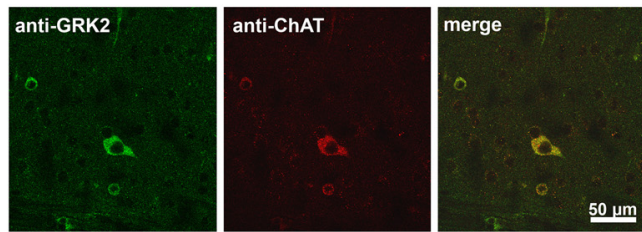

E
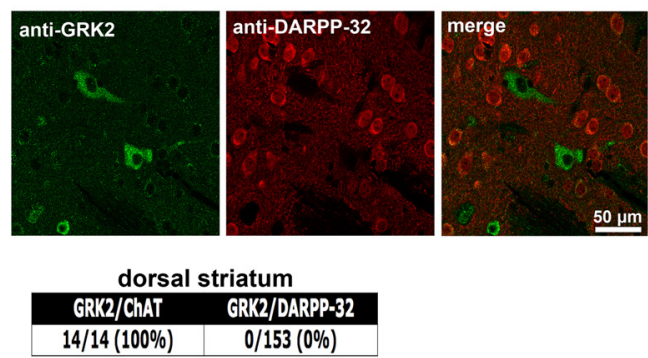

Figure 1. GRK2 expression in mouse brain. $A-C$, Brain sections prepared from C57BL/6J mice were immunostained either with a GRK2-specific antibody (anti-GRK2) or with the secondary antibody alone. Representative confocal images of GRK2 immunoreactivity throughout the brain $(\boldsymbol{A})$, in the (A3 region of the hippocampus $(\boldsymbol{B})$, or in the dorsal striatum $(\boldsymbol{C})$ are shown $(n=5$ mice). D. Western analyses of GRK2 levels in the FC, dorsal striatum (dSTR), and ventral striatum (VSTR) of C57BL/6 J mice. Representative Western blots and the corresponding densitometric analyses are shown. GRK2 levels were normalized to actin in each respective lane. Data are mean $+\mathrm{SEM} ; n=6$ mice for each group. ${ }^{* *} p<0.01$ and ${ }^{*} p<0.05$ by unpaired $t$ test. $E$, Immunofluorescence of dorsal striatal sections prepared from C57BL/6J mice that were costained with antibodies directed against either GRK2 (green) and ChAT (red) (E) or against GRK2 (green) and DARPP-32 (red) (F). A merge of both fluorescent channels in $\boldsymbol{E}$ and $\boldsymbol{F}$ is shown in the third column. G, Quantification of the number of ChAT- or DARPP-32-positive cells that were also found to be positive for GRK2 in dorsal striatal sections.

dissolved in sterile isotonic saline and injected as described at a volume of $10 \mathrm{ml} / \mathrm{kg}$ body weight.

Immunohistochemistry. Staining was performed as previously described (Daigle et al., 2011). Briefly, mice were anesthetized and brains were then fixed by transcardial perfusion of ice-cold PBS followed by $10 \%$ formalin solution (Sigma-Aldrich). Free-floating brain sections (50 $\mu \mathrm{m})$ were prepared and incubated overnight at $4^{\circ} \mathrm{C}$ in the indicated primary antibody. The primary antibodies used were as follows: GRK2 (1:500; Santa Cruz Biotechnology), DARPP-32 (dopamine- and cAMPregulated phosphoprotein of $32 \mathrm{kDa}$ ) (1:2000; BD Biosciences), ChAT (choline acetyltransferase) (1:300; Millipore), and GFP (1:5000; Abcam). Alexa dye-conjugated secondary antibodies (Life Technologies) were used to detect the primary antibody. Images $(1024 \times 1024$ pixels $)$ were acquired on an Olympus FluoView FV1000 confocal microscope.

Western analyses. Measurement of GRK2 levels in lysates from the indicated brain regions was performed as previously described (Daigle et al., 2011).

Behavioral analyses. All oxotremorine-M (Oxo-M) behavioral experiments were performed blind of genotype. For these studies, body temperature, spontaneous and drug-induced locomotor activity, and antinociceptive responses were measured as previously described (Daigle et al., 2011).

Locomotor activity. Locomotor activity was measured at $5 \mathrm{~min}$ intervals during the light phase of the cycle in an automated Omnitech Digiscan apparatus (Accuscan Instruments). Cocaine sensitization experiments were performed as previously described (Gainetdinov et al., 2003). Briefly, mice were given one injection of cocaine and then placed into the open field where activity was monitored for $90 \mathrm{~min}$, for five consecutive days. After a $1 \mathrm{~d}$ reprieve from treatment, mice were challenged on day 7 with the same dose of cocaine and again monitored in the open field.

Conditioned place preference. Conditioned place preference (CPP) was performed in a three-chamber apparatus (Med Associates) as previously described (Bohn et al., 2003). In brief, the CPP protocol consisted of preconditioning, conditioning, and postconditioning phases. During the preconditioning phase on day 1 , mice were allowed free access to all three chambers and the time spent in each compartment for a $30 \mathrm{~min}$ period was recorded. During the conditioning phase, mice were injected with cocaine ( 10 or $20 \mathrm{mg} / \mathrm{kg}$, i.p.) on days 2,4 , and 6 and with saline on days 3,5 , and 7 . The drug was randomly paired with alternating compartments, such that half of the mice received drug in one distinct compartment and the other half received drug in a different distinct compartment. On day 8 (postconditioning phase), mice were allowed free access to all three chambers and the time spent in each individual chamber was recorded for a $30 \mathrm{~min}$ period. Cocaine preference was determined by calculating the difference $(\Delta)$ in the time spent in the drug-paired chamber during the preconditioning period to the time spent in the same chamber during the postconditioning period.

Measurement of body temperature. Rectal body temperature was measured by inserting a probe from a digital thermometer (TH8, Physitemp) into the rectum.

Salivation. Salivation was measured as previously described (Gainetdinov et al., 1999; Gomeza et al., 1999b). Scoring for salivation was designated as follows: 0 = no salivation, $1=$ moderate salivation, and $2=$ pronounced salivation. Scores were normalized to $100 \%$ (score of 2) and averaged for each time point according to genotype.

Hot plate analgesia test. Analgesic responses were determined using a hot plate maintained at $58 \pm 1^{\circ} \mathrm{C}$. Animals were exposed to the hot plate and the time that elapsed until the animal responded was recorded.

Statistical analyses. All statistical analyses were performed using GraphPad Prism 4.0 software (GraphPad Software) and the results are presented as means and SEMs. A one-way or two-way ANOVA alone or with repeated measures followed was used for comparisons within genotypes, between genotypes, drug treatments, and for comparisons of treatments in the same animal that were sampled at various times.

\section{Results}

We initially performed an immunohistochemical analysis of GRK2 expression in the mouse brain to define the global distri- 
A
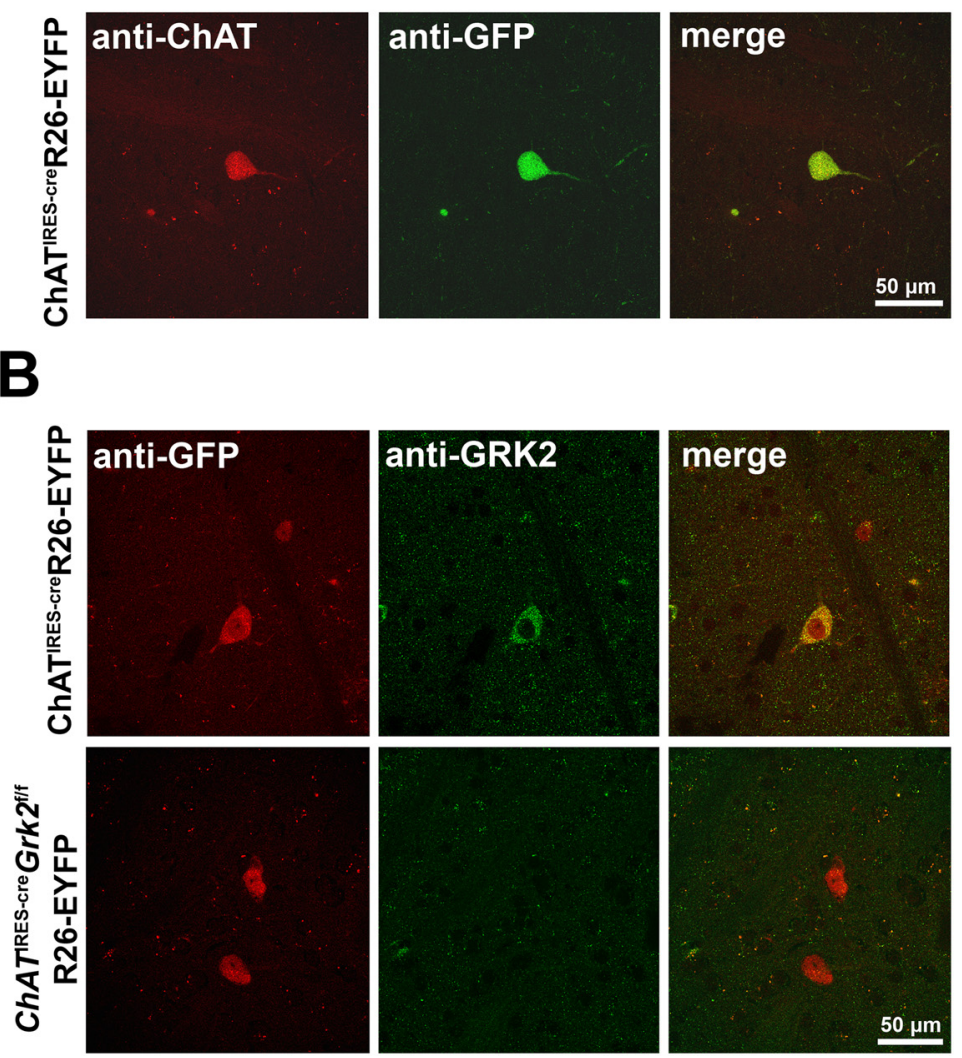

Figure 2. Selective deletion of GRK2 from cholinergic interneurons. $\boldsymbol{A}$, Confocal images of ChAT (red) and EYFP (green) immunofluorescence in dorsal striatal sections prepared from ChAT IRES- cre R26-EYFP mice. $\boldsymbol{B}$, Immunofluorescence was performed on

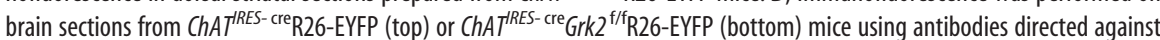
EYFP (red) and GRK2 (green).

bution of this isoform. Sagittal sections prepared from adult C57BL/6J mice were stained with a GRK2-specific antibody. The selectivity of this antibody for GRK2 over other isoforms has been previously demonstrated using purified recombinant GRK proteins (Ahmed et al., 2008a). GRK2 immunoreactivity was found distributed throughout the brain with the highest levels of expression observed in the CA3 region of the hippocampus and within the molecular layer of the cerebellum (Fig. 1A). Highermagnification images revealed the robust expression of GRK2 within the cell bodies of CA3 pyramidal neurons and also what appeared to be labeling in axonal and dendritic compartments (Fig. $1 B$ ). In contrast, GRK2 expression in the striatum was markedly lower relative to many other regions, with only large, positively stained cell bodies scattered sparsely throughout (Fig. $1 \mathrm{~A}, \mathrm{C})$. Consistent with these observations, GRK2 protein levels in the striatum were significantly reduced relative to the levels found in the frontal cortex (FC vs dorsal striatum, $p=0.058$; FC vs ventral striatum, $p=0.0107$; Fig. $1 D$ ). To determine which cell type in the striatum expressed GRK2, we costained sections with either ChAT (a marker for cholinergic neurons) or DARPP-32 (a marker for all medium spiny neurons; Fig. $1 E, F$ ). We found that all ChAT-positive neurons were also positive for GRK2, while no colocalization of GRK2 was evident with DARPP-32 (Fig. $1 E-G$ ). Our results suggest that despite the widespread distribution of this kinase throughout the brain, GRK2 expression within the striatum is highly enriched in cholinergic interneurons.

To better understand the role of GRK2 in cholinergic neurons, we crossed mice with a floxed Grk2 locus $\left(G r k 2^{\mathrm{f} / \mathrm{f}}\right)$ to animals in which Cre recombinase expression is driven by the endogenous ChAT locus (ChAT $T^{I R E S-}$ cre) to generate conditional knock-out mice $\left(C h A T^{I R E S-c r e} G r k 2^{\mathrm{fff}}\right)$ and control littermates $\left(G r k 2^{\mathrm{f} / \mathrm{f}}\right)$. ChAT $T^{\text {IRES-cre }}$ mice were also crossed to a Rosa26-floxed-stop-EYFP (R26-EYFP) reporter mouse line to verify Cre-mediated recombination by immunostaining. In agreement with the expected expression pattern, we found that EYFP immunoreactivity was restricted to ChATpositive neurons within the striatum (Fig. $2 A$ ). To determine whether GRK2 was selectively deleted from cholinergic neurons in the conditional $\mathrm{KO}$ animals, EYFP and GRK2 costaining was analyzed in $C h A T^{I R E S-}$ ${ }^{\mathrm{cre}} \mathrm{Grk} 2{ }^{\mathrm{f} / \mathrm{f}} \mathrm{R} 26-\mathrm{EYFP}$ mice. As expected, in control sections prepared from ChAT ${ }^{\text {IRES- }}$ creR26-EYFP mice, neurons that expressed ChAT also expressed GRK2 (Fig. 2B). This was in stark contrast to the staining observed in $\mathrm{KO}$ animals $\left(C h A T^{I R E S-\mathrm{cre}} \mathrm{Grk}^{\mathrm{ff/f}}\right.$ R26-EYFP), where no GRK2 immunoreactivity was observed in ChAT neurons or throughout the striatum (Fig. $2 B$ ). These results confirm that $\mathrm{KO}$ mice lack GRK2 in cholinergic neurons and further demonstrate the cellular specificity of GRK2 expression in striatal cholinergic interneurons.

Since stimulation of the cholinergic system has been shown to promote hypothermia and hypoactivity, we next wanted to determine whether these central cholinergic responses were altered by the selective deletion of GRK2. We found that core body temperature of $C h A T^{\text {IRES-cre }} G r k 2^{\mathrm{f} / \mathrm{f}}$ mice did not differ from control animals $\left(34.9 \pm 0.08^{\circ} \mathrm{C}\right.$ vs $34.6 \pm 0.1^{\circ} \mathrm{C}$, respectively) and similarly, no difference was observed in locomotor activity between genotypes in a given $1 \mathrm{~h}$ period $(1757.2 \pm 75.4 \mathrm{~cm}$ for control mice vs $1570.0 \pm 195 \mathrm{~cm}$ for KO mice; Fig. $3 \mathrm{~A}, B$ ) or in body weight (data not shown). Because GRK2 has classically been shown to be engaged following receptor activation, we next evaluated the behavioral responses of $C h A T^{\text {IRES-cre }} G r k 2^{\mathrm{f} / \mathrm{f}}$ mice to Oxo-M, a nonselective muscarinic acetylcholine receptor agonist. Oxo-Minduced behaviors include hypothermia, hypolocomotion, salivation and antinociception in mice (Gainetdinov et al., 1999). Oxo-M treatment $(0.1 \mathrm{mg} / \mathrm{kg}$, i.p. $)$ produced robust hypothermia in both genotypes (Fig. 3C); however, the magnitude of the response was significantly reduced in $C h A T^{\mathrm{IRES}-\text { cre }} \mathrm{Grk} 2^{\mathrm{f} / \mathrm{f}}$ mice (for treatment, $F_{(1,28)}=140.64, p<0.0001$; interaction, $F_{(1,28)}=$ $12.02, p=0.0017)$. While both genotypes also became less active following Oxo-M treatment $(0.05 \mathrm{mg} / \mathrm{kg}$, i.p.; Fig. $3 D)$, the initial response of $C h A T^{\text {IRES-cre }} G r k 2^{\text {f/f }}$ mice was significantly blunted relative to control animals (interaction, $F_{(5,84)}=2.82, p=0.0211$; genotype, $F_{(1,84)}=6.13, p=0.0153$; interaction genotype $\times$ time, $\left.F_{(5,84)}=15.29, p<0.0001\right)$. Additionally, ChAT ${ }^{\text {IRES-cre }} G r k 2^{\text {f/f }}$ mice challenged with Oxo-M exhibited decreased salivation relative to control animals $30 \mathrm{~min}$ postinjection (interaction, $F_{(2,36)}=$ $5.64, p=0.0074$; genotype, $F_{(1,36)}=4.41, p=0.0501$; interaction genotype $\times$ time, $F_{(2,36)}=3.50, p=0.0408 ;$ Fig. $\left.3 D\right)$. In contrast, Oxo-M-induced analgesia was pronounced in both $C h A T^{\mathrm{IRES}-\text {-rre }}$ $G r k 2^{\mathrm{f} / \mathrm{f}}$ and $G r k 2^{\mathrm{f} / \mathrm{f}}$ mice (Fig. $3 F$ ), with no difference observed 
between genotypes (for treatment, $F_{(1,28)}=$ $13.74, p=0.0009$; genotype, $F_{(1,28)}=0.58$, $p=0.4540$; interaction, $F_{(1,28)}=0.10, p=$ $0.7569)$. Together, these data indicate that the deletion of GRK2 from cholinergic neurons does not grossly alter cholinergic function but, rather, reduces sensitivity to select muscarinic acetylcholine receptor-mediated behavioral responses.

Previous studies have reported that the genetic deletion of G-protein-coupled receptor kinase 6 (GRK6) promotes cocaine supersensitivity in mice, while GRK2 heterozygous animals exhibit a very modest enhancement of cocaine-induced locomotor activity (Gainetdinov et al., 2003, 2004). To determine whether the selective deletion of GRK2 in cholinergic neurons alters behavioral responsiveness to cocaine, locomotor activity was measured following acute or subchronic cocaine administration (Fig. 4). $C h A T^{\text {IRES-cre }} \mathrm{Grk} 2^{\mathrm{f} / \mathrm{f}}$ mice given a single injection of cocaine at the indicated doses responded in a similar manner to control animals (interaction, $F_{(23,644)}=0.97, p=$ 0.4972; genotype, $F_{(1,644)}=1.81, p=$ 0.1892; time, $F_{(23,644)}=32.55, p<0.0001$; Figure $4 A, B)$. To determine whether sensitization to cocaine was altered by GRK2 deficiency, we evaluated locomotor activity in $G r k 2^{\mathrm{f} / \mathrm{f}}$ and $C h A T^{\mathrm{IRES}-\mathrm{cre}} \mathrm{Grk2} \mathrm{f}^{\mathrm{f} / \mathrm{f}}$ mice following daily injections of cocaine $(20 \mathrm{mg} /$ kg, i.p.; Fig. 4C-E). The initial response of both genotypes to cocaine (day 1 ) did not differ significantly (interaction, $F_{(23,322)}=$ $0.64, p=0.8978$; genotype, $F_{(1,322)}=5.54$, $p=0.0337$; time, $F_{(23,322)}=13.54, p<$ $0.0001)$ at all times evaluated with the exception of the time of peak response $(p<$ 0.5 by Bonferroni post hoc test) (Fig. $4 C$, left). Repeated cocaine injections produced robust sensitization with no observed differences between genotypes on day 7 (interaction, $F_{(23,322)}=0.97, p=$ 0.4993 ; genotype, $F_{(1,322)}=0.01, p=$ 0.9209 ; time, $F_{(23,322)}=18.79, p<0.0001$; Fig. $4 C$, right). Analysis of the sum of the total distance traveled in the $10 \mathrm{~min}$ postinjection of cocaine revealed a significant increase in activity in both genotypes on day 7 , but no significant difference in the activity of $C h A T^{\text {IRES-cre }} G r k 2^{\mathrm{f} / \mathrm{f}}$ mice relative to control animals was found (interaction, $F_{(1,14)}=1.99, p=0.1802$; genotype, $F_{(1,14)}=0.01, p=0.9117$; time, $\left.F_{(1,14)}=10.59, p=0.0058\right)$ (Fig. $4 D$ ). Last, a conditioned place preference paradigm was used to determine whether the rewarding properties of cocaine were affected by the selective deletion of GRK2. In these studies we observed a similar level of preference in both genotypes at the two doses of cocaine tested (Fig. $4 E$ ). Collectively, these results suggest that GRK2 deficiency in cholinergic neurons does not alter cocaine-induced psychomotor activation, sensitization, or the rewarding properties of the drug.

A

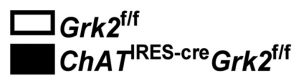

B
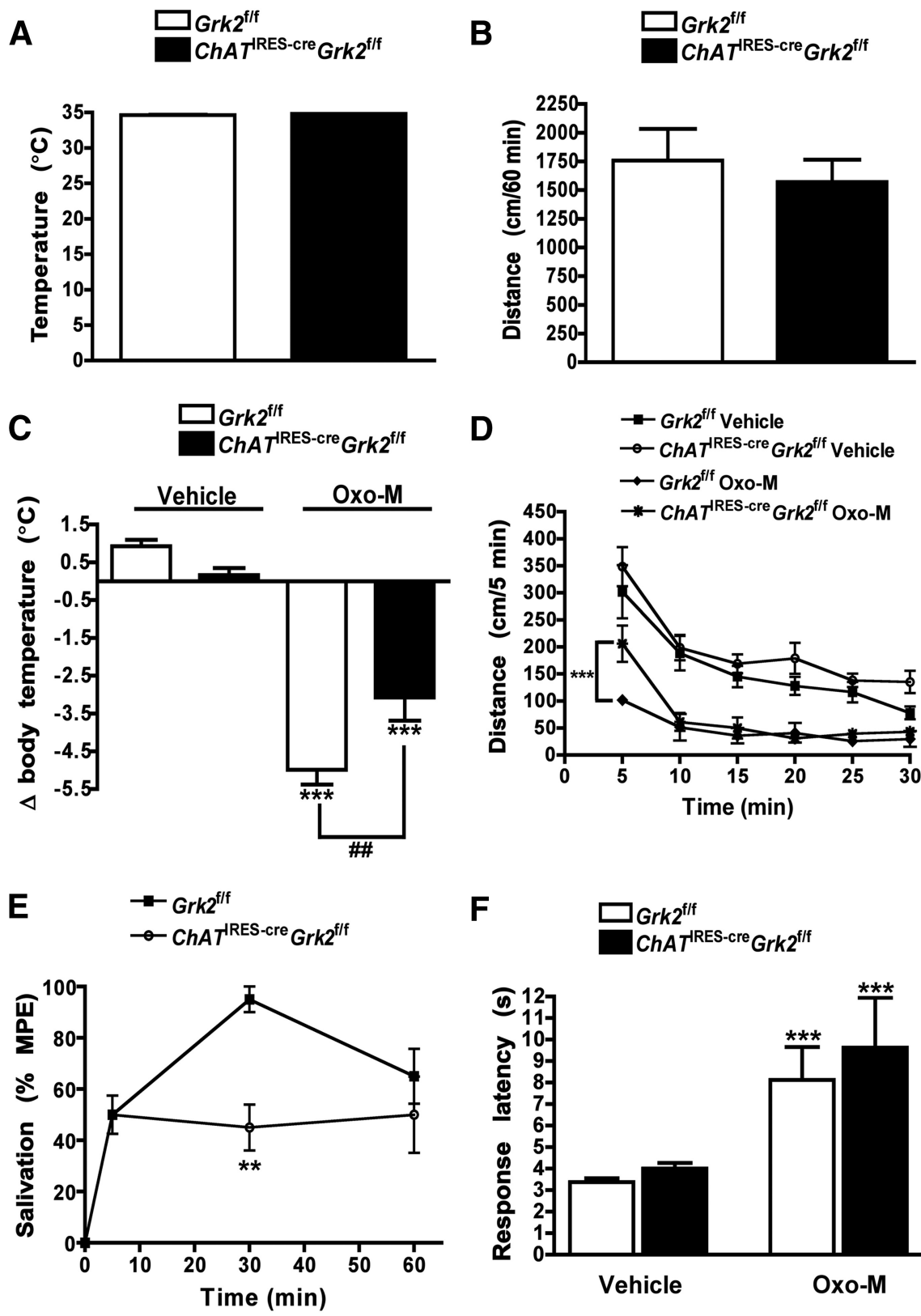

$\mathbf{F}$
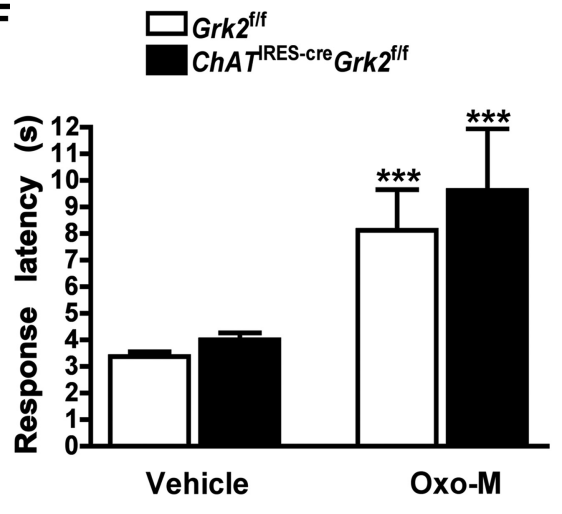

Figure 3. $\mathrm{ChAT}^{\mathrm{IRES}-\mathrm{cre}} \mathrm{Grk2}{ }^{\mathrm{f} / \mathrm{f}}$ mice exhibit reduced sensitivity to select $0 \mathrm{xo}$-M-induced behavioral changes. $A, B$, Basal body temperature and spontaneous locomotor activity of drug naive $\mathrm{Grk}^{\mathrm{f} / \mathrm{f}}$ and $\mathrm{ChAT} \mathrm{T}^{\mathrm{RES}-\mathrm{cre}} \mathrm{Grk2} \mathrm{F}^{\mathrm{f} / \mathrm{f}}$ mice. C, Mice were administered either vehicle or $0 \times 0-M\left(0.1 \mathrm{mg} / \mathrm{kg}\right.$, i.p.) and body temperature was measured before and 30 min after injection. ${ }^{* * *} p<0.0001$, vehicle vs $0 \times 0-M$ treatment within genotypes and ${ }^{\# \#} p<0.01$ for comparison between genotypes of the drug effect by two-way ANOVA. D, Locomotor activity time course of $G r k 2^{\mathrm{f} / \mathrm{f}}$ and $C h A T^{\text {TRES- cre }} \mathrm{Grk} 2^{\mathrm{f} / \mathrm{f}}$ mice following the administration of either vehicle or Oxo-M $\left(0.05 \mathrm{mg} / \mathrm{kg}\right.$, i.p.). ${ }^{* * *} p<0.0001$ for comparison between genotypes of the drug effect by two-way repeated-measures ANOVA. $E$, $0 \times 0-M$-induced ( $0.05 \mathrm{mg} / \mathrm{kg}$, i.p.) salivation in indicated animals (\% MPE = percentage maximum possible effect). ${ }^{* *} p<0.01$ for comparison between genotypes of the drug effect by two-way repeated-measures ANOVA. F, 0xo-M-induced (0.1 $\mathrm{mg} / \mathrm{kg}$, i.p.) analgesia in Grk2/f and ChATR ${ }^{\mathrm{fRS}-\text { cre }} \mathrm{Grk} 2^{\mathrm{f} / \mathrm{f}}$ mice. ${ }^{* * *} p<0.0001$, vehicle vs $0 \times 0-M$ treatment within genotypes by two-way ANOVA. Data are means + SEM; $n=8-10$ mice for each group.

\section{Discussion}

The lack of viable GRK2 KO mice has proven to be a significant obstacle in the study of the function of this kinase in the adult brain. Additionally, the scarcity of information regarding the distribution of GRK2 in various cell populations has prevented more directed genetic studies. Here we report the expression of GRK2 in the mouse brain and identify the principal cell type in which this isoform is expressed within the striatum. These expression results confirm and extend a previous report on GRK2 


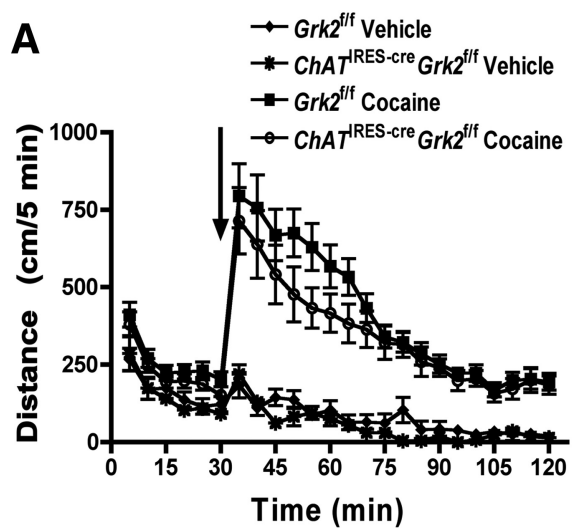

C

Day 1

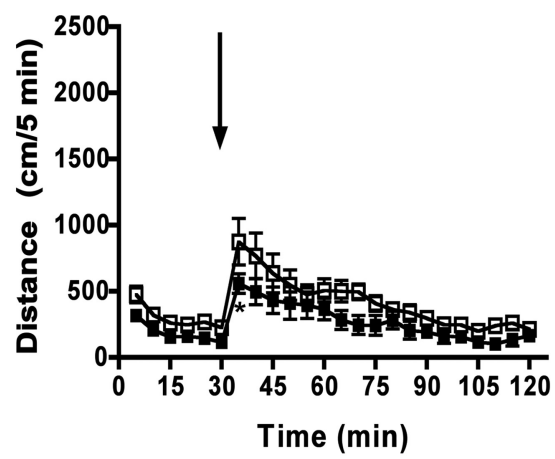

D
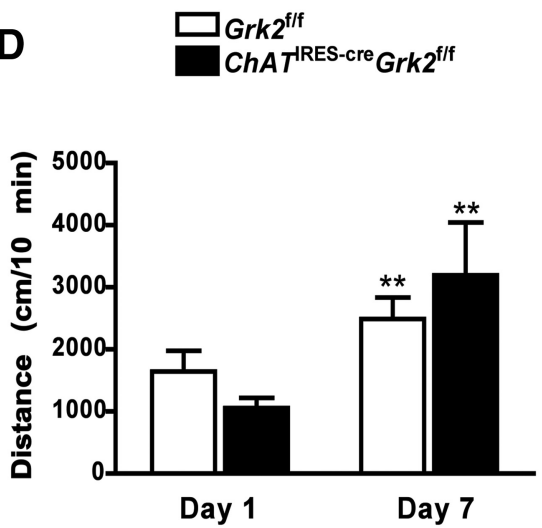

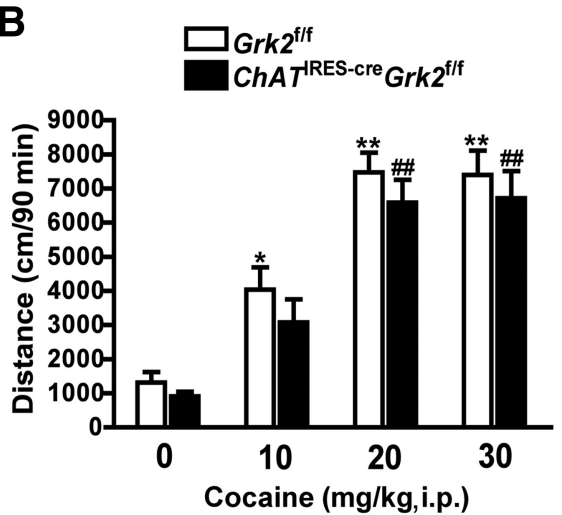

Day 7
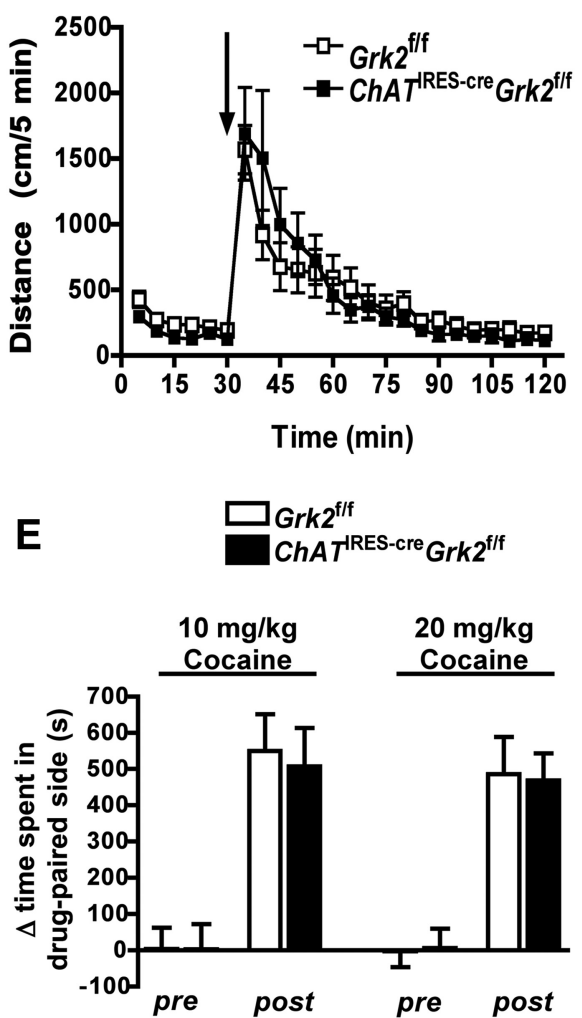

conditional $\mathrm{KO}$ mice results in less pronounced hypothermia, hypolocomotion, and salivation. Studies from subtype selective muscarinic receptor $\mathrm{KO}$ mice have revealed that $\mathrm{M}_{2}$ receptors mainly mediate the hypothermic effect of oxotremorine, while $\mathrm{M}_{1}$ and $\mathrm{M}_{4}$ receptors modulate spontaneous locomotor activity, and three subtypes $\left(M_{1}, M_{3}\right.$, and $\left.M_{4}\right)$ regulate agonistinduced secretion of saliva from salivary glands (Gomeza et al., 1999a; Gomeza et al., 1999b; Gerber et al., 2001; Miyakawa et al., 2001; Bymaster et al., 2003). Therefore, reduced responsiveness of GRK2 conditional $\mathrm{KO}$ mice to Oxo-M may reflect reduced activity of multiple muscarinic receptor subtypes that are expressed in diverse cholinergic neuron populations, such as in striatal interneurons or in extrastriatal cholinergic projection neurons. Blunted muscarinic receptor responses may be a direct consequence of reduced surface expression or altered signaling. It was reported in cell lines and cultured neurons that overexpression of GRK2 enhances agonist-driven muscarinic receptor $\left(\mathrm{M}_{1}\right.$, $\mathrm{M}_{2}$, and $\mathrm{M}_{4}$ ) internalization and desensitization (Tsuga et al., 1998; Holroyd et al., 1999). In apparent contrast, our findings appear to support a role for GRK2 as a positive regulator of muscarinic receptor function, perhaps via actions as an intermediary kinase in a critical signaling cascade. Alternatively, it is possible that GRK2 promotes muscarinic receptor desensitization and internalization in response to stimulation with different agonists such as pilocarpine, or is possibly engaged differently in diverse neuronal populations.

Altered behavioral responsiveness to Oxo-M may also be due to reduced presynaptic muscarinic receptor function (i.e., autoreceptors). For example, in the absence of GRK2, striatal $\mathrm{M}_{4}$ autoreceptor activity may be reduced, which would result in increased levels of acetylcholine. Because striatal acetylcholine levels are known to regulate locomotor activity, it is conceivable that the observed reduction in Oxo-M-mediated hypoactivity may be due to altered cholinergic tone. The relationship between acetylcholine levels and GRK2 function would therefore be

localization in rat brain (Arriza et al., 1992). Using a conditional $\mathrm{KO}$ approach, we demonstrate that GRK2 in cholinergic neurons is required for the full expression of select Oxo-M-mediated behaviors. These observations suggest that GRK2 modulates muscarinic receptor function in vivo, possibly by altering agonistmediated desensitization or trafficking.

While we did not find evidence that GRK2 regulates the cholinergic system under basal conditions, we did find that the pharmacological activation of muscarinic receptors in GRK2 an interesting open topic for future investigation.

One major effect of cocaine treatment is increased dopamine receptor signaling in various regions within the mesolimbic system. Since dopamine receptor signaling can be affected by various GRKs and because previous studies in which cholinergic interneurons were either ablated or optogenetically manipulated reported altered behavioral sensitivity to cocaine, we evaluated the effects of this stimulant in GRK2 conditional KO mice (Hikida et al., 2001; Gainetdinov et al., 2003; Witten et al., 2010). 
In our study we found that cocaine promotes similar levels of locomotor activity, behavioral sensitization and conditioned place preference in conditional $\mathrm{KO}$ animals relative to control animals. These results suggest that GRK2 function within cholinergic neuronal populations does not regulate dopaminergic signaling.

In summary, our results demonstrate that the loss of GRK2 in cholinergic neurons leads to markedly reduced behavioral sensitivity to muscarinic receptor stimulation. Considering the supersensitivity to muscarinic agonists observed in GRK5-deficient animals, it would appear that the GRK2 family member has a unique functional role in that it positively regulates central cholinergic responses. Given that hypercholinergic tone is associated with several movement disorders, such as Parkinson's disease and dystonia, this functional divergence between isoforms may be exploited in future work to explore the therapeutic potential of selective GRK2 inhibitors.

\section{References}

Ahmed MR, Gurevich VV, Dalby KN, Benovic JL, Gurevich EV (2008a) Haloperidol and clozapine differentially affect the expression of arrestins, receptor kinases, and extracellular signal-regulated kinase activation. J Pharmacol Exp Ther 325:276-283.

Ahmed MR, Bychkov E, Gurevich VV, Benovic JL, Gurevich EV (2008b) Altered expression and subcellular distribution of GRK subtypes in the dopamine-depleted rat basal ganglia is not normalized by l-DOPA treatment. J Neurochem 104:1622-1636.

Arriza JL, Dawson TM, Simerly RB, Martin LJ, Caron MG, Snyder SH, Lefkowitz RJ (1992) The G-protein-coupled receptor kinases beta ARK1 and beta ARK2 are widely distributed at synapses in rat brain. J Neurosci 12:4045-4055.

Bezard E, Gross CE, Qin L, Gurevich VV, Benovic JL, Gurevich EV (2005) L-DOPA reverses the MPTP-induced elevation of the arrestin2 and GRK6 expression and enhanced ERK activation in monkey brain. Neurobiol Dis 18:323-335.

Bohn LM, Gainetdinov RR, Sotnikova TD, Medvedev IO, Lefkowitz RJ, Dykstra LA, Caron MG (2003) Enhanced rewarding properties of morphine, but not cocaine, in beta(arrestin)-2 knock-out mice. J Neurosci 23:10265-10273.

Bymaster FP, Carter PA, Yamada M, Gomeza J, Wess J, Hamilton SE, Nathanson NM, McKinzie DL, Felder CC (2003) Role of specific muscarinic receptor subtypes in cholinergic parasympathomimetic responses, in vivo phosphoinositide hydrolysis, and pilocarpine-induced seizure activity. Eur J Neurosci 17:1403-1410.

Daigle TL, Wetsel WC, Caron MG (2011) Opposite function of dopamine D1 and $N$-methyl-D-aspartate receptors in striatal cannabinoid-mediated signaling. Eur J Neurosci 34:1378-1389.

Gainetdinov RR, Bohn LM, Walker JK, Laporte SA, Macrae AD, Caron MG, Lefkowitz RJ, Premont RT (1999) Muscarinic supersensitivity and impaired receptor desensitization in $\mathrm{G}$ protein-coupled receptor kinase 5-deficient mice. Neuron 24:1029-1036.

Gainetdinov RR, Bohn LM, Sotnikova TD, Cyr M, Laakso A, Macrae AD, Torres GE, Kim KM, Lefkowitz RJ, Caron MG, Premont RT (2003) Dopaminergic supersensitivity in $G$ protein-coupled receptor kinase 6-deficient mice. Neuron 38:291-303.
Gainetdinov RR, Premont RT, Bohn LM, Lefkowitz RJ, Caron MG (2004) Desensitization of $\mathrm{G}$ protein-coupled receptors and neuronal functions. Annu Rev Neurosci 27:107-144.

Gerber DJ, Sotnikova TD, Gainetdinov RR, Huang SY, Caron MG, Tonegawa S (2001) Hyperactivity, elevated dopaminergic transmission, and response to amphetamine in M1 muscarinic acetylcholine receptordeficient mice. Proc Natl Acad Sci U S A 98:15312-15317.

Gomeza J, Shannon H, Kostenis E, Felder C, Zhang L, Brodkin J, Grinberg A, Sheng H, Wess J (1999a) Pronounced pharmacologic deficits in M2 muscarinic acetylcholine receptor knockout mice. Proc Natl Acad Sci U S A 96:1692-1697.

Gomeza J, Zhang L, Kostenis E, Felder C, Bymaster F, Brodkin J, Shannon H, Xia B, Deng C, Wess J (1999b) Enhancement of D1 dopamine receptormediated locomotor stimulation in $\mathrm{M}(4)$ muscarinic acetylcholine receptor knockout mice. Proc Natl Acad Sci U S A 96:10483-10488.

Hikida T, Kaneko S, Isobe T, Kitabatake Y, Watanabe D, Pastan I, Nakanishi S (2001) Increased sensitivity to cocaine by cholinergic cell ablation in nucleus accumbens. Proc Natl Acad Sci U S A 98:13351-13354.

Holroyd EW, Szekeres PG, Whittaker RD, Kelly E, Edwardson JM (1999) Effect of G protein-coupled receptor kinase 2 on the sensitivity of M4 muscarinic acetylcholine receptors to agonist-induced internalization and desensitization in NG108-15 cells. J Neurochem 73:1236-1245.

Jaber M, Koch WJ, Rockman H, Smith B, Bond RA, Sulik KK, Ross J Jr, Lefkowitz RJ, Caron MG, Giros B (1996) Essential role of betaadrenergic receptor kinase 1 in cardiac development and function. Proc Natl Acad Sci U S A 93:12974-12979.

Managò F, Espinoza S, Salahpour A, Sotnikova TD, Caron MG, Premont RT, Gainetdinov RR (2012) The role of GRK6 in animal models of Parkinson's Disease and L-DOPA treatment. Sci Rep 2:301.

Matkovich SJ, Diwan A, Klanke JL, Hammer DJ, Marreez Y, Odley AM, Brunskill EW, Koch WJ, Schwartz RJ, Dorn GW 2nd (2006) Cardiacspecific ablation of G-protein receptor kinase 2 redefines its roles in heart development and beta-adrenergic signaling. Circ Res 99:996-1003.

Miyakawa T, Yamada M, Duttaroy A, Wess J (2001) Hyperactivity and intact hippocampus-dependent learning in mice lacking the M1 muscarinic acetylcholine receptor. J Neurosci 21:5239-5250.

Premont RT, Gainetdinov RR (2007) Physiological roles of G proteincoupled receptor kinases and arrestins. Annu Rev Physiol 69:511-534.

Raehal KM, Schmid CL, Medvedev IO, Gainetdinov RR, Premont RT, Bohn LM (2009) Morphine-induced physiological and behavioral responses in mice lacking G protein-coupled receptor kinase 6. Drug Alcohol Depend 104:187-196.

Schroeder JA, McCafferty MR, Unterwald EM (2009) Regulation of dynamin 2 and $G$ protein-coupled receptor kinase 2 in rat nucleus accumbens during acute and repeated cocaine administration. Synapse 63:863-870.

Tsuga H, Okuno E, Kameyama K, Haga T (1998) Sequestration of human muscarinic acetylcholine receptor hm1-hm5 subtypes: effect of $\mathrm{G}$ protein-coupled receptor kinases GRK2, GRK4, GRK5 and GRK6. J Pharmacol Exp Ther 284:1218-1226.

Wang H, Wu LJ, Kim SS, Lee FJ, Gong B, Toyoda H, Ren M, Shang YZ, Xu H, Liu F, Zhao MG, Zhuo M (2008) FMRP acts as a key messenger for dopamine modulation in the forebrain. Neuron 59:634-647.

Witten IB, Lin SC, Brodsky M, Prakash R, Diester I, Anikeeva P, Gradinaru V, Ramakrishnan C, Deisseroth K (2010) Cholinergic interneurons control local circuit activity and cocaine conditioning. Science 330:16771681. 